\title{
Time Series Analysis of Sexual Assault Case Characteristics and the 2007-2008 Period of Post- Election Violence in Kenya
}

\author{
Michael P. Anastario ${ }^{1 *}$, Monica Adhiambo Onyango ${ }^{2}$, Joan Nyanyuki ${ }^{3}$, Karen Naimer ${ }^{3}$, Rachel Muthoga ${ }^{3}$, \\ Susannah Sirkin ${ }^{3}$, Kelle Barrick ${ }^{1}$, Martijn van Hasselt ${ }^{1}$, Wilson Aruasa ${ }^{4}$, Cynthia Kibet ${ }^{4}$, Grace Omollo ${ }^{5}$ \\ 1 RTI International, Research Triangle Park, North Carolina, United States of America, 2 Boston University School of Public Health, Boston, Massachusetts, United States of \\ America, $\mathbf{3}$ Physicians for Human Rights, Boston, Massachusetts, United States of America, 4 Moi Teaching and Referral Hospital, Eldoret, Kenya, $\mathbf{5}$ Nakuru Provincial \\ General Hospital, Nakuru, Kenya
}

\begin{abstract}
Background: Following the declaration that President Mwai Kibaki was the winner of the Kenyan presidential election held on December 27, 2007, a period of post-election violence (PEV) took place. In this study, we aimed to identify whether the period of PEV in Kenya was associated with systematic changes in sexual assault case characteristics.

Methods and Findings: Medical records of 1,615 patients diagnosed with sexual assault between 2007 and 2011 at healthcare facilities in Eldoret $(n=569)$, Naivasha $(n=534)$, and Nakuru $(n=512)$ were retrospectively reviewed to examine characteristics of sexual assault cases over time. Time series and linear regression were used to examine temporal variation in case characteristics relative to the period of post-election violence in Kenya. Key informant interviews with healthcare workers at the sites were employed to triangulate findings. The time series of sexual assault case characteristics at these facilities were examined, with a specific focus on the December 2007-February 2008 period of post-election violence. PraisWinsten estimates indicated that the three-month period of post-election violence was associated with a 22 percentagepoint increase in cases where survivors did not know the perpetrator, a 20 percentage-point increase in cases with more than one perpetrator, and a 4 percentage-point increase in cases that had evidence of abdominal injury. The post-election violence period was also associated with an 18 percentage-point increase in survivors waiting $>1$ month to report to a healthcare facility. Sensitivity analyses confirmed that these characteristics were specific to the post-election violence time period.
\end{abstract}

Conclusion: These results demonstrate systematic patterns in sexual assault characteristics during the PEV period in Kenya.

Citation: Anastario MP, Adhiambo Onyango M, Nyanyuki J, Naimer K, Muthoga R, et al. (2014) Time Series Analysis of Sexual Assault Case Characteristics and the 2007-2008 Period of Post-Election Violence in Kenya. PLoS ONE 9(8): e106443. doi:10.1371/journal.pone.0106443

Editor: Paula Braitstein, Indiana University and Moi University, United States of America

Received December 4, 2013; Accepted May 16, 2014; Published August 29, 2014

Copyright: (c) 2014 Anastario et al. This is an open-access article distributed under the terms of the Creative Commons Attribution License, which permits unrestricted use, distribution, and reproduction in any medium, provided the original author and source are credited.

Funding: Support for this work was provided by Physicians for Human Rights (PHR). PHR employees (KN, RM, SS, JN) contributed to study design, data interpretation, and manuscript editing.

Competing Interests: Three of the study authors are currently or were affiliated with organizations that advocate for the prevention of mass atrocities, protection of internationally guaranteed rights, and/or prosecution of those who violate human rights: Physicians for Human Rights (KN, RM, SS, JN). Two of the study authors (WA, GO) are serving or have served as directors of the clinic from which the data were obtained. All authors have declared that no financial conflicts of interest exist.

* Email: manastario@rti.org

\section{Introduction}

Recent armed conflicts have demonstrated the high incidence of sexual violence in modern warfare [1-3], which may occur due to opportunistic environmental conditions, strategies to terrorize, expel, or subjugate victims, and/or in settings where captives have been taken [4]. At the population level, alterations in patterns of sexual assault during times of conflict may be indicative of, and/or characterize mass rape.

Medical evidence of sexual assault is likely to vary by injury definition, examiner training and experience, and examination technique [5]. As such, using medical record data to establish a mass rape can be challenging. However, research methods can provide efficient strategies to establish and characterize the occurrence of a mass rape within a jurisdiction [4]. Over time, sexual assaults may exhibit trends or features within a given population. Significant deviations in sexual assault trends may indicate exogenous impacts to the pattern of criminal activity [6]. In the context of conflicts, case characteristics of sexual assaults during mass rapes may logically deviate from non-conflict related assaults.

Following the disputed Kenyan presidential election held on December 27, 2007, there was a period of post-election violence (PEV) that spanned from December 2007 to February 2008. Crimes against humanity - such as murder, deportation or forcible transfer and persecution, rape, and other forms of sexual violence - were alleged to have occurred [7]. Using data derived from medical record reviews of sexual assault cases reporting to three health facilities located in the Rift Valley from 2007-2011, our objective was to identify whether the three-month PEV time 
period was associated with systematic changes in sexual assault case characteristics using medical records from three healthcare facilities.

\section{Methods}

Quantitative and qualitative methods were used to triangulate the characteristics of sexual assault cases documented during the PEV period at Moi Teaching and Referral Hospital, Nakuru Provincial General Hospital, and Naivasha District Hospital. Quantitative methods included retrospective review and time series analysis of medical records that included a diagnosis of sexual violence at the three facilities between January 2007 and December 2011. Qualitative methods included conducting key informant, semi-structured interviews with healthcare clinicians at each of these facilities. This research was approved by the Institutional Research and Ethics Committee of Moi Teaching and Referral Hospital, the Boston University Medical Center Institutional Review Board (IRB), and the Research Triangle Institute International IRB.

\section{Medical record review}

Medical records for all patients seen at each of the three facilities with a diagnosis of sexual violence from January 2007 to December 2011 were extracted by a study team during March and April, 2013. In order to inform our power analyses, we used a previous study to inform an estimate of the proportions of soft tissue injuries experienced in women who were assaulted by a stranger in comparison to a known assailant, where a between group proportion of 0.1770 was observed [8]. For the purposes of this power analysis, we used the known/unknown status of the assailant to estimate expectedly elevated rates of injuries during a conflict period. With at least 200 medical records in the specific time periods of interest and 400 in the comparison periods, and assuming the proportion in the time period of interest is 0.552 ( 0.3750 under the null hypothesis) and the proportion in the comparison periods to be 0.3750 , the estimated group sample sizes of 200 interest period and 400 comparison period medical records achieved $>95 \%$ power to detect the 0.1770 difference with a significance level of 0.050 , using a test statistic with a two-sided $\mathrm{Z}$ test with pooled variance. Although the time series analysis would pool observations by month, we wanted to maximize the stability of estimates that would be "folded" into each month.

Given that, as documentation improved, more records were available in later years, we aimed to oversample the entire population of medical records for 2007 and 2008, with sampling intervals used to select sexual assault case records derived from 2009, 2010, and 2011. Sampling intervals were determined by taking the remaining differences between 600 and the sum of 2007 and 2008 medical records, and creating an interval for years 2009, 2010, and 2011. A structured data collection guide was used to extract, code, and quantify specific case characteristics from the medical record regarding the sexual assault (e.g., more than one perpetrator, specific injuries). Consent was not obtained for use of medical record data - rather, patient records were anonymized and de-identified prior to analysis.

A team of data collectors was trained at each facility to systematically extract and code elements of the patient medical records. Data collection teams were managed and codes were systematically reviewed for quality by a local co-investigator.

As it relates to this study, the standard of care for sexual assault survivors on the day they present to the healthcare facilities studied includes taking a history, physical exam, laboratory investigations, STI prophylaxis, emergency contraception, analgesics, tetanus toxoid, and referral. If possible the health providers encourage survivors to report the case to the police on the same day, if this had not happened by the time survivors come to the hospital. Medical records (Post Rape Care forms) are filled by nurses, clinical officers and physicians.

A PEV assault variable was developed for cases where the documented date of sexual assault fell within the three months during which the PEV took place (December 2007, January 2008, February 2008). Given that data were collapsed by month to create the units of analysis for the time series analyses, this was the greatest degree of specificity possible to capture likely PEV cases. All other sexual assault cases falling outside of this three-month PEV time period were treated as the comparison group. Case characteristics were coded as binary variables, which became percentages ranging from 0 to 1.0 at the month level. Percentages at the month level represent the percentage of all sexual assault cases during a specific time period that exhibited a case characteristic of interest.

\section{Qualitative interviews}

Qualitative in-depth interviews were conducted with clinicians (medical officers, clinical officers and nurses) at the three hospitals using a semi-structured interview guide. A total of 23 clinicians $(6$ in Eldoret, 10 in Naivasha, and 7 in Nakuru) participated in a 30120 minute audiotaped interview. The clinicians were either currently working with, or had worked with sexual violence cases between 2007 and 2011. All study participants provided verbal consent to decrease the potential for breach of confidentiality. Verbal consent was documented by the interviewer - this consent procedure was approved by the ethics committees.

\section{Data analysis}

Data were analyzed using STATA 10 statistical software. Data were cleaned to eliminate cases from the analytic dataset that failed logic and consistency checks. To examine trends in case characteristics over time, we collapsed the dataset by month of assault and calculated the percentage of cases for a given month that exhibited a case characteristic of interest. We examined the first 10 autocorrelations for each outcome series, and calculated the Durbin-Watson statistics based on standard least squares regression to examine autocorrelation in the residuals. We used the Prais-Winsten regression estimator to account for potential autocorrelation in the errors and to assess changes in outcomes during the PEV period, controlling for survivor gender and days lagged between assault and presentation. For outcomes in which the first-order autocorrelation was statistically significant, we also estimated an autoregressive model of order 1, or AR(1) model. This model specification contained a one-period lag of the outcome as an independent variable and was adjusted for survivor gender and days lagged between assault and presentation.

In order to further ensure that associations between the PEV period and outcomes were not artifacts of general record keeping during 2007/2008, we conducted a sensitivity analysis using a "dummy" measure to represent the three-month time period immediately preceding the PEV period (November, October, and September 2007) where medical records should be of relatively comparable quality to those of the PEV period. Sensitivity analyses were conducted for significant PEV findings identified in the time series analyses.

Transcripts of audiotapes from qualitative data were checked against the recordings for accuracy. Two researchers conducted inductive content analysis on all transcripts and independently identified codes and broad themes after which they reached a 
consensus. Nvivo9 computer software was used to organize interview content into sub-categories and broad themes.

\section{Results}

\section{Descriptive characteristics of the sample (Table 1)}

In total, 1,615 medical records were identified with sexual assault diagnoses, with 569 cases derived from Eldoret, 534 cases from Naivasha, 512 cases from Nakuru. Cases that did not qualify for inclusion failed logic and consistency checks. Cases were collapsed into months for the time series analyses (Table S1 in File $\mathrm{S} 1)$. Table 1 provides descriptive characteristics of the sample by the mean monthly percentages of the case characteristic for PEV (95 cases, 3 months) and non-PEV (1,520 cases, 57 months) periods. On average, cases in the PEV period showed a greater percentage-point increase in a one-month lag between date of assault and date of presentation to healthcare facility $(0.28$ in PEV cases, 0.10 in non-PEV cases, $\mathrm{p}=.003)$. Cases in the PEV period also showed a greater percentage-point increase in the perpetrator being unknown to the victim $(0.45$ in PEV cases, 0.23 in non-PEV cases, $\mathrm{p}=.001)$, more than one perpetrator being involved in the sexual assault $(0.35$ in PEV cases, 0.13 in non-PEV cases, $\mathrm{p}<.001)$, and abdominal injuries (0.07 in PEV cases, 0.03 in non-PEV cases, $\mathrm{p}=.025)$. The monthly time series for case characteristics that were significantly associated with the PEV period are shown in Figure 1. A relative "spike" in these case characteristics is apparent following the December 2007 observation (the first month of the PEV).

Days lagged between assault and presentation to health facility. We analyzed the monthly percentage of cases with more than a one month lag in presentation to a health facility. The first-order autocorrelation was not significant $(p=0.233)$ and insignificant for two or more lags. The estimated coefficient of the PEV period (beta $=0.18, \quad \mathrm{SE}=0.06$ ) was highly significant $(p=0.003)$, indicating that the PEV period was associated with an 18 percentage-point increase in cases showing a $>1$ month lag in presentation to a health facility.

Survivor did not know the perpetrator. The first-order autocorrelation was not significant $(\mathrm{p}=0.166)$, and insignificant for two or more lags. After adjusting for sex and lag between date of assault and presentation to the health facility, the estimated coefficient of the PEV period (beta $=0.22, \mathrm{SE}=0.07$ ) was highly

Table 1. Descriptive Characteristics of the sample, by PEV period.

\begin{tabular}{|c|c|c|c|}
\hline & $\begin{array}{l}\text { Mean monthly prevalence } \\
\text { in non-PEV months }{ }^{\mathrm{a}}\end{array}$ & $\begin{array}{l}\text { Mean monthly prevalence } \\
\text { in PEV months }\end{array}$ & \\
\hline & & & $\mathbf{P}^{c}$ \\
\hline \multicolumn{4}{|l|}{ Background characteristics } \\
\hline Eldoret & 0.29 & 0.57 & .631 \\
\hline Naivasha & 0.36 & 0.19 & .201 \\
\hline Nakuru & 0.35 & 0.24 & .514 \\
\hline Gender (male) & 0.07 & 0.09 & .563 \\
\hline $\begin{array}{l}\text { Lag between assault and } \\
\text { presentation, mean (SD) }\end{array}$ & 0.10 & 0.28 & .003 \\
\hline \multicolumn{4}{|l|}{ Case characteristics } \\
\hline Did not know perpetrator & 0.23 & 0.45 & .001 \\
\hline More than 1 perp & 0.13 & 0.35 & $<.001$ \\
\hline \multicolumn{4}{|l|}{ Type of assault: } \\
\hline Oral & 0.01 & 0.01 & .594 \\
\hline Vaginal & 0.89 & 0.86 & .550 \\
\hline Anal & 0.08 & 0.11 & .364 \\
\hline Weapon used & 0.10 & 0.14 & .523 \\
\hline Condom used & 0.05 & 0.03 & .524 \\
\hline Rape was witnessed & 0.61 & 0.55 & .871 \\
\hline History of previous rape & 0.08 & 0.05 & .324 \\
\hline \multicolumn{4}{|l|}{ Injury: } \\
\hline Anogenital & 0.70 & 0.64 & .539 \\
\hline Head/neck & 0.08 & 0.06 & .472 \\
\hline Limbs & 0.08 & 0.05 & .621 \\
\hline Chest & 0.02 & 0.01 & .612 \\
\hline Back & 0.02 & 0.02 & .719 \\
\hline Abdomen & 0.03 & 0.07 & .025 \\
\hline Skin & 0.02 & 0.02 & .870 \\
\hline Emotional distress & 0.25 & 0.38 & .872 \\
\hline
\end{tabular}

a Based on 1,520 cases over 57 non-PEV months.

${ }^{\mathrm{b}}$ Based on 95 cases over 3 PEV months.

'Probability values derived from unadjusted, bivariate Prais-Winsten analyses.

doi:10.1371/journal.pone.0106443.t001 


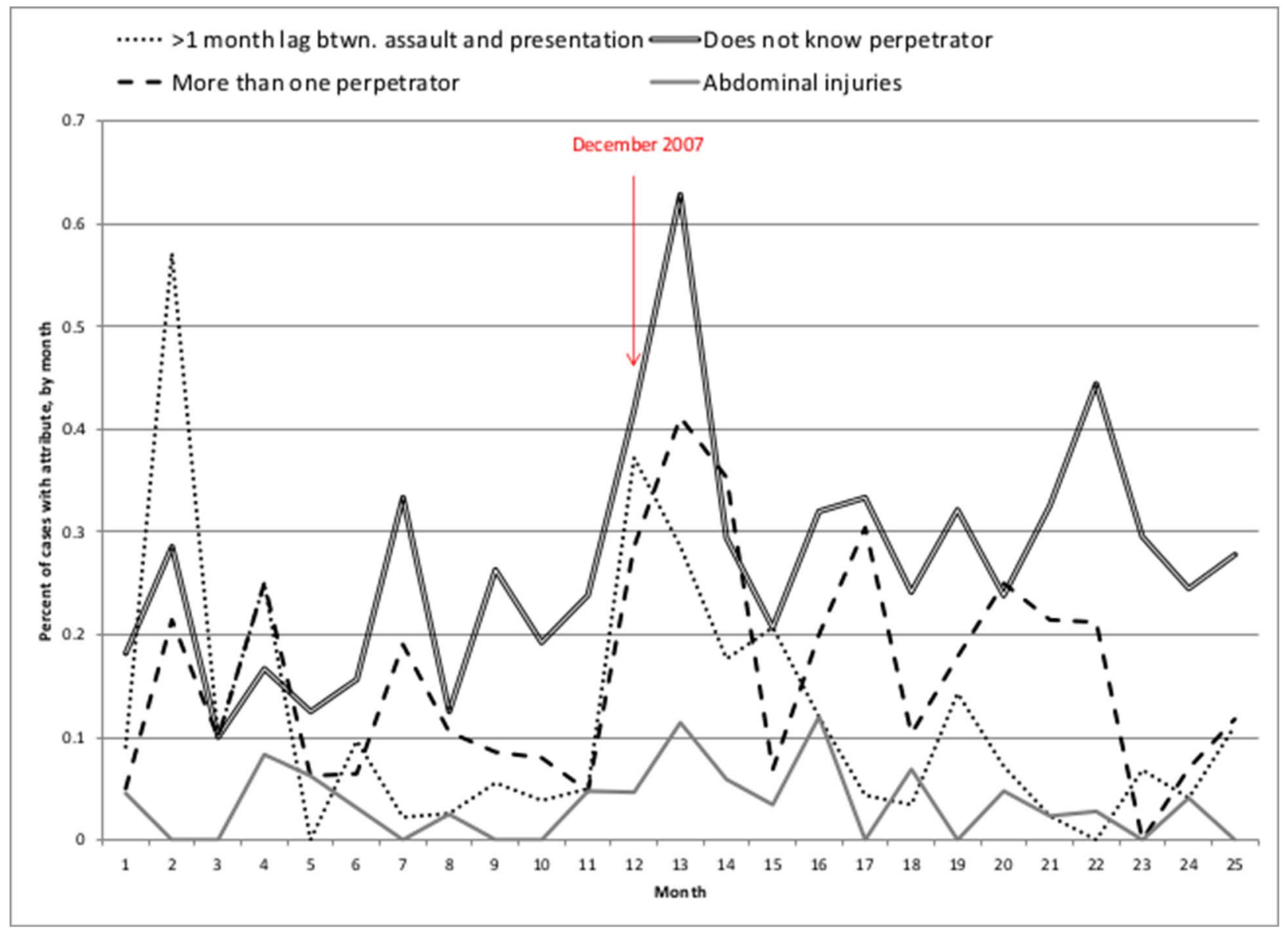

Figure 1. Percent of cases with significant characteristic, by month (January 2007-January 2009)*. ${ }^{*}$ Series has been abbreviated to display multiple characteristics during PEV period.

doi:10.1371/journal.pone.0106443.g001

significant $(\mathrm{p}=.002)$ (Table 2), indicating that the PEV period was associated with a 22 percentage-point increase in cases where the survivor did not know the perpetrator.

Multiple perpetrators for a sexual assault incident. The first-order autocorrelation was marginally significant $(\mathrm{p}=0.03)$ and insignificant for two or more lags. The autocorrelation and partial autocorrelation functions suggested that the percentage of cases where the survivor reported more than one perpetrator did not follow an autoregressive process. After adjusting for sex and lag between date of assault and presentation to the health facility, the Prais-Winsten estimate of the coefficient of the PEV period (beta $=0.20, \mathrm{SE}=0.06)$ was highly significant $(\mathrm{p}=0.001)($ Table 2), indicating that the PEV period was associated with a 20 percentage-point increase in cases where the survivor reported more than one perpetrator. We also estimated an $\mathrm{AR}(1)$ model, controlling for a one-month lag of $\mathrm{y}_{\mathrm{t}}$, as a secondary specification. This produced an identical effect size for the PEV period (beta $=0.20, \mathrm{SE}=0.07, \mathrm{p}=0.003$ ).

Abdominal injury. The first- and higher-order autocorrelations were not statistically significant. After adjusting for sex and lag between date of assault and presentation to the health facility, the estimated coefficient of the PEV period (beta $=0.04$, $\mathrm{SE}=0.02)$ was significant $(\mathrm{p}=0.048)$ (Table 2), indicating that the PEV period was associated with a four percentage-point increase in cases with a documented abdominal injury.

Table 2. Prais-Winsten models for key outcomes.

\begin{tabular}{llll}
\hline & & & \\
\hline Outcome & beta (SE) & $\mathbf{P}$ & Durbin-Watson $^{-}$ \\
\hline$>1$ month lag in presentation $^{\mathrm{a}}$ & $0.18(0.06)$ & 0.003 & 1.99 \\
Did not know perpetrator $^{\mathrm{b}}$ & $0.22(0.07)$ & 0.002 & 1.99 \\
More than 1 perpetrator $^{\mathrm{b}}$ & $0.20(0.06)$ & 0.001 & 1.93 \\
Abdominal injury $^{\mathrm{b}}$ & $0.04(0.02)$ & 0.048 & 1.99 \\
\hline
\end{tabular}

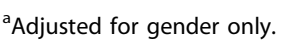

${ }^{\mathrm{b}}$ Adjusted for gender and lag between date of assault and presentation to a healthcare facility.

doi:10.1371/journal.pone.0106443.t002 


\section{Sensitivity analyses}

No significant differences were observed for cases drawn from the dummy period for the case characteristics that were significantly associated with the PEV period in the Prais-Winsten estimates.

\section{Qualitative findings}

Participants described that during the PEV, few survivors presented to hospital facilities. Lack of knowledge regarding the need to immediately access a health facility, material barriers to accessing a health facility, and the competing responsibility of meeting basic needs (security, shelter, food, childcare) were described as primary barriers to presentation during the PEV period.

Participants described infrastructure issues (blocked roads, violence outside their homes) and general insecurity of the environment as barriers to access during the PEV. One participant described that the delay in presentation:

...was because of stigmatization and, of course, fear, because...who are raping them or defiling the children were people in authority, like the police, the GSU [General Service Unit].

Further, meeting basic material needs was described as taking precedence over survivors reporting to or seeking care at a health facility. As one clinician described:

...they also didn't have food, they also didn't have shelter, and most of us were busy taking care of their other needs - like where will they stay, what will they eat? ...You're a mother, with children, and you're raped, and your house is burnt down. At that time, the priority is: where will your children stay to run for safety. So it does not even occur to you that you have been raped and you may get HIV. So it was a silent emergency, as compared to shelter and food, which were obvious emergencies.

In Eldoret, it was described that following the Waki Commission (the Commission of Inquiry on Post Election Violence) proceedings, survivors of sexual assault began presenting to health facilities. After testifying before the commission, survivors were referred to the clinic.

During the interviews, healthcare workers also described that among the few people who presented at the clinics claiming to have been raped during the PEV period, gang rape was frequently reported. In addition, the majority of the women who presented late with claims of sexual assault were either pregnant or wanted to be tested for the HIV infection.

\section{Discussion}

In sexual assaults at three healthcare facilities, we found that the December 2007-February 2008 PEV period was associated with survivors waiting $>1$ month to report to a health facility, not knowing the perpetrator, reporting more than one perpetrator, and having documented abdominal injuries. Sensitivity analyses revealed that none of the PEV associations were significantly replicated during the dummy period immediately preceding the PEV. Our findings of systematic alterations in the series of sexual assault cases during the PEV period have implications for establishing the occurrence of mass rape, and characterizing the sexual assaults that took place during the PEV.

This is the first study to use medical record review to illustrate systematic alterations in sexual assault case characteristics during the PEV period. One study conducted at Kenyatta National Hospital examined medical records to establish a relative increase of sexually abused persons treated at the hospital in the year 2007 compared to the years 2006 and 2008 [9]. Our study illustrates change in the months (vs. year) associated with the PEV period, and also shows how case characteristics of sexual assault varied. Conflict-related features of mass rape that have been documented in other conflicts include the use of racial epithets used during attacks in which sexual assaults took place, a relatively high male victimization rate, gang rape, and/or the reported victimization of other individuals $[10,11]$. Our findings (particularly concerning gang rape) suggest a change in sexual assault perpetration patterns during the PEV period that is consistent with the documentation of mass rape in conflict settings.

After adjustment, there was more than a 20 percentage-point increase in PEV period cases where the survivor did not know the perpetrator. Research suggests that survivors of sexual assault generally know the perpetrator, and that the more intimate the relationship between a survivor of sexual assault and the perpetrator, the more likely a case is to be processed [12-16]. Along with the qualitative evidence of gang rape, our findings illustrate a PEV-specific deviation in the perpetrators of sexual assault during the PEV period. Further, our findings corroborate the testimony of survivors who testified before the Commission of Inquiry on Post-Election Violence (Waki Commission), where the majority reported gang rape during the $\mathrm{PEV}$, including gang rape perpetrated by civilians, security agents, and police [17].

Further, we found that PEV survivors more often waited $>1$ month following their assault to present to a health facility. This lag period was in part due to barriers of accessibility, security, fear, and lack of community knowledge. Most medical forensic evidence of sexual assault at the patient level could not be readily collected after this type of lag period - particularly viable DNA evidence. However, this lag period itself is a significant finding. Our qualitative findings suggested that several PEV assault survivors sought medical care as a result of pregnancy. A post-hoc analysis revealed that $23.2 \%$ of $\mathrm{PEV}$ assaults arrived at the clinic seven to nine months following their PEV assault (correspond with the third trimester of pregnancy). In comparison, only $0.4 \%$ of non$\mathrm{PEV}$ assaults exhibited this same lag. Even after controlling for this lag, a pattern of case characteristics was still significantly associated with the PEV period. An extended lag period between date of assault and presentation to a medical facility has also been documented in another resource restricted setting affected by armed conflict [18].

One unexpected finding was the increase in the documentation of abdominal injuries associated with the PEV period. There are several possible reasons for why this case characteristic was significantly associated with the PEV period. One possible physiological explanation is that the abdominal injuries documented in the current study were the result of infections derived from the assault. It is also possible that abdominal pain reported was the embodiment of trauma, or the chief presenting complaint of the survivor. In a study of persistent pain in survivors of torture, female abdominal/pelvic/genital pain was associated with sexual assault [19]. Further research is needed to understand the mechanisms underlying the link between abdominal injuries and the PEV period.

\section{Limitations}

Our study has several limitations. First, data are representative of sexual assault cases that were documented in medical records at three facilities within Kenya's Rift Valley. It is likely that a large number of PEV cases were never reported to a health facility. Further, our findings did not document sexual homicides, only case characteristics of living patients. A strength of our study was 
using time series analysis in conjunction with medical record review to gain efficiencies that would be lost in conducting a larger, cross-sectional population base survey that rely on survivor recall. Second, the quality of medical records varied over time and by location. Despite our use of a trained data collection team and use of a standardized instrument for extracting case elements from sexual violence files, time-dependent trends in documentation and record keeping may have impacted the rates reported. However, our use of time series analysis and the sensitivity measure (the three months immediately preceding the 2007 PEV) suggests that the variation in the PEV cases represents a true departure from the underlying 'series' of sexual assault cases occurring outside of the PEV period. Finally, we were unable to quantitatively capture/ report age of victim due to the medical record entry form.

\section{Conclusion}

In this study, which used time series analysis of medical record data to test for systematic changes in sexual assault characteristics for cases presenting to health facilities in the Rift Valley region, we found that cases of assault during the PEV period were associated with an increased percentage of cases where the survivor waited to present to a health facility following the assault, did not know the perpetrator, reported more than one perpetrator, and had evidence of abdominal injury in the medical record. These results

\section{References}

1. Dahrendorf N, Shifman P (2004) Sexual violence in conflict and post-conflict: A need for more focused action. Refugee Survey Quarterly 23: 7-19.

2. Olugic M (1998) Emodiment of terror: Gendered violence in peactime and wartime in Croatia and Bosnia-Herzegovina. Medical Anthropology Quarterly 12: $31-50$

3. Swiss S, Jennings PJ, Aryee GV, Brown GH, Jappah-Samukai RM, et al. (1998) Violence against women during the Liberian civil conflict. JAMA 279: 625-629.

4. Agirre Aranburu X (2010) Sexual Violence beyond Reasonable Doubt: Using Pattern Evidence and Analysis for International Cases. Leiden Journal of International Law 23: 609-627.

5. Sugar NF, Fine DN, Eckert LO (2004) Physical injury after sexual assault: findings of a large case series. Am J Obstet Gynecol 190: 71-76.

6. Schissel B (1996) Law reform and social change: A time-series analysis of sexual assault in Canada. Journal of Criminal Justice 24: 123-138.

7. International Criminal Court (2012). Summary of decision in the two Kenya cases. International Criminal Court. 23 January 2012. Available: http://www. icc-cpi.int/NR/exeres/7036023F-C83C-484E-FDD-0DD37E568E84.htm.

8. Stermac LE, Du Mont JA, Kalemba V (1995) Comparison of sexual assaults by strangers and known assailants in an urban population of women. CMAJ 153: 1089-1094.

9. Kuria MW, Omondi L, Olando Y, Makanyengo M, Bukusi D (2013) Is sexual abuse a part of war? A 4-year retrospective study on cases of sexual abuse at the Kenyatta National Hospital Kenya. 4.

10. Hagan J, Rymond-Richmond W, Palloni A (2009) Racial targeting of sexual violence in Darfur. Am J Public Health 99: 1386-1392. illustrate systematic alterations in sexual assault case characteristics during the 2007/2008 period of PEV in Kenya.

\section{Supporting Information}

File S1 This file contains Table $S 1$ and Figure S1. Table S1. Time series data for sexual assault case characteristics, 20072011. Figure S1. Variables for Table S1.

(PDF)

\section{Acknowledgments}

The authors would like to thank Dr. Catherine DeAngelis, Judith Bite, Edith Chege, Marcy Chitai, DeDe Dunevant, Monica Grotto, Mercy Kigundu, Emily Kiragu, Dr. Coleen Kivlahan, Catherine Koech, Moses Ndege, Deborah Ngeno, Kennedy Okello and Doris Tuitoek, and Eliza Young for their contributions in making this a successful research endeavor. We also would like to thank the health clinicians in Kenya who so kindly participated as key informants and shed light on the PEV situation.

\section{Author Contributions}

Conceived and designed the experiments: MA MAO RM KN SS. Performed the experiments: JN WA CK GO. Analyzed the data: MA MAO KB MVH. Wrote the paper: MA MAO KB MVH.

11. Tsai AC, Eisa MA, Crosby SS, Sirkin S, Heisler M, et al. (2012) Medical evidence of human rights violations against non-Arabic-speaking civilians in Darfur: a cross-sectional study. PLoS Med 9: e1001198.

12. Ingemann-Hansen O, Brink O, Sabroe S, Sorensen V, Charles AV (2008) Legal aspects of sexual violence-does forensic evidence make a difference? Forensic Sci Int 180: 98-104

13. Janisch S, Meyer H, Germerott T, Albrecht UV, Schulz Y, et al. (2010) Analysis of clinical forensic examination reports on sexual assault. Int J Legal Med 124: 227-235.

14. McLean I, Roberts SA, White C, Paul S (2011) Female genital injuries resulting from consensual and non-consensual vaginal intercourse. Forensic Sci Int 204: 27-33.

15. Bouffard JA (2000) Predicting type of sexual assault case closure from victim, suspect, and case characteristics. Journal of Criminal Justice 28: 527-542.

16. McGregor MJ, Du Mont J, Myhr TL (2002) Sexual assault forensic medical examination: is evidence related to successful prosecution? Ann Emerg Med 39: 639-647.

17. (2008) Report of the Findings of the Commission of Inquiry into the PostElection Violence in Kenya.

18. Bartels SA, Scott JA, Leaning J, Kelly JT, Joyce NR, et al. (2012) Demographics and care-seeking behaviors of sexual violence survivors in South Kivu province, Democratic Republic of Congo. Disaster Med Public Health Prep 6: 393-401.

19. Williams AC, Pena CR, Rice AS (2010) Persistent pain in survivors of torture: a cohort study. J Pain Symptom Manage 40: 715-722. 